\title{
O Lugar das comunidades na preservação do património arqueológico. Um projeto de investigação. \\ Maria João Cândido ${ }^{1}$
}

\section{Resumo}

Neste artigo apresentamos o projeto de investigação em curso, no âmbito do Doutoramento em Museologia pela ULHT, onde se propõe mapear as sítios arqueológicos do concelho de Setúbal, identificando os sítios com relevância para a (s) comunidade (s) e com os quais se identificam, caracterizando as memórias associadas aos sítios arqueológicos com ligação às comunidades e analisar a relação que as comunidades estabelecem com estes sítios. A par da relação que a comunidade estabelece com o sítio arqueológico, são analisadas as formas de divulgação e de comunicação da arqueologia como ciência e enquanto prática, versando sobre termos como arqueologia clandestina e arqueologia de trincheira.

Palavras-chave; Memória; Comunidade; Identidade; Práticas arqueológicas; Arqueologia de trincheira

\footnotetext{
1 Doutoranda em Museologia na Universidade Lusófona de Lisboa,, licenciou-se em História, variante de Arqueologia pela Universidade de Coimbra em 1997. Desde então tem desenvolvido projetos no âmbito da Arqueologia urbana e Museologia. Coordena o Setor de Património e Arqueologia da Câmara Municipal de Setúbal desde o ano 2000.
} 
O Lugar das comunidades na preservação do património...

\section{Abstract}

In this article we present the research project underway in the PhD in Museology by ULHT, where it is proposed to map the archaeological sites of Setúbal, identifying the sites with relevance to the community (s) and with which they identify, characterizing the memories associated to the archaeological sites with connection to the communities and to analyze the relation that the communities establish with these sites. Along with the relationship established between the community and the archaeological site, the methods of dissemination and communication of archeology as a science and as a practice are analyzed, proposing terms such as Clandestine Archeology and Trench Archeology.

Keywords: Memory; Community; Identity; Archaeological practices; Archeology of trench

Quando terminei o secundário, entre os 17 e 18 anos, indecisa entre escolher Arqueologia ou Antropologia como percurso universitário, resolvi participar num campo de férias internacional promovido pelo Instituto Português da Juventude. Os campos de férias abrangiam áreas como biologia, natureza, trabalhos de âmbito florestral e arqueologia.

O campo de férias, com a duração de 15 dias, consistia na participação de uma escavação arqueológica no Castelo de Juromenha. Trata-se de uma pequena aldeia entre o Alandroal e Elvas, junto às margens do rio Guadiana, em pleno alentejo.

O castelo, de fundação islâmica, localizado num sítio estratégico de defesa desde a pré-história encontrava-se num estado degradado, o que lhe dava um ar romântico de ruína.

Com o professor Fernando Branco Correia, a quem devo o despertar da minha paixão pela arqueologia, lá iamos todos os dias de manhã bem cedo em direção ao castelo para continuar com os trabalhos. Nunca mais me esqueci do primeiro dia, quando fomos 
buscar a chave do Castelo que era guardada pela Dona Mariana, dona do único café que existia na aldeia. Senti que estava a entrar na "casa" das gentes de Juromenha, daquela comunidade que guardava o seu castelo com tanto primor, mesmo no seu estado de ruína.

E todos os dias lá íamos buscar a chave ao café da Dona Mariana.

Nos anos seguintes o programa de campos de férias encerrou e o professor Fernando Branco Correia continuou com os trabalhos num regime de voluntariado, com alunos e jovens das redondezas. Fui para Juromenha todos os anos em Agosto até 1996, no último ano da minha licenciatura.

Anos mais tarde a lembrança da chave do castelo guardada no café da Dona Mariana, marcou o meu percurso profissional e fez me pensar na relação que se estabelece entre arqueologia e comunidade, património e comunidade e museologia e comunidade.

No decorrer da minha actividade, como arqueóloga no munícipio de Setúbal, realizei vários acompanhamentos de obras no centro histórico da cidade de Setúbal, nos bairros mais típicos de pescadores e na zona de comércio. Alguns dos trabalhos arqueológicos consistiram no acompanhamento de abertura de valas para instalação de canalizações, rede de esgoto e outras infraestruturas. Nestas circusntãncias, a arqueologia e o arqueólogo mantém um contacto em directo com a comunidade, que não resiste à curiosidade de ir ver se apareçe algum tesouro e acaba por ficar a ver e a conversar com o arqueólogo (realidade que não se aplica a todos os arqueólogos). E nestes 17 anos de práctica de arqueologia urbana, nos vários acompanhamentos de abertura de valas que realizei, tentei sempre comunicar a arqueologia ao explicar o que estava a fazer e porquê, a sensibilizar para o património pedindo que me contassem histórias sobre a rua, como era, do que se lembravam e do que os seus pais e avós lhes tinham contado. A partir deste diálogo, surge naturalmente o interesse 
O Lugar das comunidades na preservação do património...

pelo antigo, pelo quotidiano de quem viveu na mesma rua, no mesmo bairro, séculos antes, crescendo a vontade de o conhecer e preservar.

Como arqueóloga sinto o património arqueológico da região de Setúbal como um elemento identitário e que deve ser preservado, mas como também sou setubalense sempre questionei com sentiam as comunidades o património arqueológico. Sentem no como seu? Tem consciência que alguns dos locais com lendas religiosas e algumas procissões tem na sua origem e história associada património arqueológico, que remonta nalguns casos à ocupação de época romana? Foram questões como estas que me incentivaram a apresentar um projecto de investigação no programa de doutoramento em Museologia da Universdidade Lusófona de Humanidades e Tecnologias de Lisboa, por este estar direcionado para uma museologia social.

"Sem memória, sem a leitura dos restos do passado, não pode haver o reconhecimento da diferença, nem a tolerância das ricas complexidades e instabilidades de identidades pessoais e culturais, políticas e nacionais. Compreende-se então que os indivíduos e a sociedade precisam do passado para sustentar suas identidades e nutrir a perspectiva do futuro" (HUYSSEN, 2000).

As iniciativas de preservação do patrimônio arqueológico têm se multiplicado, em especial desde a década de 1980, muitas vezes ligadas à afirmação de identidades. Vários autores tem refletido sobre o tema, tais como Manuel Castells, Pierre Nora e Andréas Huyssen.

Segundo Nora (Nora, 1993), o lugar de memória encerra em si o registo e aquilo que o transcende, o sentido simbólico. Os lugares da memória são espaços onde a memória se fixou, locais 
onde grupos ou povos se identificam e se reconhecem, formando a identidade e o pertencimento.

Para Castells, a busca pela identidade coletiva ou individual tornou-se uma fonte primordial na busca de significado no tempo histórico que vivemos, constituído por fluxos globais mas caracterizado pela desestruturação das organizações, pela deslegitimação das instituições, do enfraquecimento de importantes movimentos sociais e expressões culturais efémeras (Castells, 1999,23).

Como nos descreve Andréas Huyssen (HUYSSEN, 2000) na obra Seduzidos pela Memória, vivemos o paradoxo de tudo destruir, de tornarmos obsoleto o próprio presente e de, ao mesmo tempo, buscarmos formas de documentar tudo, guardar tudo, preservar tudo, e de nos voltarmos para imagens de um "passado", de uma "memória" que chega quase até o presente. A sua reflexão diz nos que os objetos obsoletos tronam-se colecionáveis com uma comercialização em massa da nostalgia, como se o objetivo fosse conseguir a recordação total e a memória tornou se uma obsessão. Mas Huyssen também nos diz que este processo deve ser analisado na sua relação com os media, que o amplifica, tornando a memória (o acesso a esta) aparentemente mais disponível e mediatizada, mas que mais facilmente cai em esquecimento. 0 passado está consolidado na paisagem e preservado nos lugares e é ele que dá o suporte mais sólido na busca pela diferença. A procura pela identidade dos lugares é importante para a preservação das tradições mas também pode ser perigosa se levada a extremos. (Abreu, 1996).

Sobre a memória dos lugares e a memória coletiva, um não existe sem o outro e a memória de um lugar é construída por camadas e cada individuo tem também uma memória individual. Como refere Halbwachs na sua obra La memoire colletive, a distinção entre memória coletiva e memória histórica tem a ver com o facto da memória histórica estar isolada num determinado 
O Lugar das comunidades na preservação do património...

momento ou período, que o distingue do momento anterior ou do seguinte. A memória coletiva é, portanto, contínua e define-se por adição de referências e enlaces com múltiplas ligações (ao antepassado, ao pessoal e ao familiar, ao local, ao acontecimento, a alterações técnicas e económicas, a costumes culturais) (Halbwachs, 1950). Mesmo em casos mais extremos de grandes transformações no espaço ou abandono do local, a memória da cultura anterior permanece, por vezes, na toponímia. É analisando a toponímia de um território, que o arqueólogo consegue, muitas vezes, identificar locais com ocupações antigas.

A identidade de um lugar está também associada à continuidade do seu uso, em contínua construção e a apropriação torna-se um processo "contra a alienação", conforme nos diz Lefebvre em Le Droit á la Ville publicada em 1968. A associação entre espirito e lugar remonta à época romana e a expressão Genius Loci diz respeito ao conjunto de características socioculturais, arquitetónicas, de linguagem, de hábitos, que caracterizam um lugar, um ambiente, uma cidade. Na Declaração de Québec, em 2008 o espirito do lugar assume um papel fundamental na museologia e é definido como o conjunto de bens materiais e imateriais, físicos e espirituais que dão sentido, valor, emoção e mistério ao lugar.

Para Castells, a identidade pode ser entendida como fonte de significado de um povo, que se constrói e se caracteriza pela multiplicidade de matéria prima de várias origens (histórica, geográfica, biológica, institucional, religiosa) dando origem a uma identidade comunitária (Castells, 2003,3). Hughes de Varine (Varine,1987) entende a comunidade com um grupo que vive num determinado território, que partilha de um conjunto de elementos simbólicos e que é consciente das semelhanças e diferenças que os caracterizam.

$\mathrm{Na}$ resistência ao processo de individualização as pessoas agrupam-se em organizações comunitárias, muitas com origem na 
religião e que ganham com o tempo o sentimento de pertença coletiva e até mesmo de uma identidade cultural. Em Setúbal, por exemplo, existem duas comunidades de pescadores com características que os diferenciam quer na pesca praticada ou na imagem e procissão religiosa a que se associam, quer nas memórias associadas a cada bairro. Estes dois bairros, carregados de história e assentes em vestígios de ocupação mais antiga, são também espaços com graves problemas sociais. O museu e a arqueologia, na sua atuação, devem ter uma relação de proximidade com a comunidade e as suas realidades.

O Museu Local, enquanto promotor de desenvolvimento, não pode actuar de forma descontextualizada dos problemas locais da sua área de influência e das pessoas que formam a comunidade local, ou seja, o museu não pode desvincular-se dos problemas da contemporaneidade como consequência de poder vir a actuar em isolamento. (Primo, 2006,48)

Nesta abordagem, a sociomuseologia desempenha um papel fundamental, porquanto a sua abordagem multidisciplinar consolida a museologia com um recurso para o desenvolvimento social e económico e assenta a sua intervenção social no património, adequando as estruturas museológicas aos condicionalismos da sociedade contemporânea (Moutinho,1993,8). Portanto, as ações patrimoniais e, também a Arqueologia, devem estar agregadas a ações de cidadania.

Tal como na Museologia, que viu nascer nos anos 60 um novo entendimento e uma nova denominação, a Nova Museologia, também na Arqueologia assistimos a novas questões que são levantadas (Nova arqueologia ou Arqueologia Processual). O objeto é encarado como indicador de processos socioeconómicos e 
O Lugar das comunidades na preservação do património...

revelador da sociedade que o criou, manipulou e descartou (Olsen, 2013 , 25). Os materiais são indicadores de processos passados, ainda que não possam ser considerados espelhos do que aconteceu no passado.

Os objetos são assim encarados como meios para o estudo do passado, ou seja, para a compreensão de sociedades e culturas passadas, para alcançar o "índio", o "primitivo" por detrás do artefacto (Olsen, 2013, 23-24).

No pós-processualismo, apesar da contestação e reação às questões processualistas também "desmaterializou" os objetos, estudando-os enquanto símbolos, metáforas, procurando o seu significado social e cultural e tentando estabelecer biografias das coisas que se relacionariam com as biografias dos seres humanos que criaram ou conviveram e morreram com os tais objetos.

A fenomenologia exerceu grande influência na Arqueologia pós-processual, particularmente na arqueologia da paisagem. 0 espaço deixa de ser entendido apenas como um conjunto de unidades mensuráveis mas como uma rede de proximidades e familiaridades experienciadas.

O termo Arqueologia Simétrica emerge sobretudo no Norte da Europa e Estados Unidos da América no início do século XXI, principalmente pela mão de M. Shanks, B. Olsen, T. Webmoor e C. Witmore. Esta pretende sobretudo a superação das velhas dicotomias que constroem os discursos acerca do passado, como sujeito-objeto, passado-presente, natureza-cultura. No entanto, esta "nova negociação de relações duais" não significa "um novo tipo de arqueologia" (Shanks, 2007, 292). Nenhum dos autores indexa este projeto a uma das escolas teóricas em Arqueologia e sublinham que esta abordagem não pretende a conciliação de posições teóricas ou a superação do pós-processualismo. Bebem inspiração em autores pós-humanistas, principalmente em Michel Serres, Bruno Latour, Donna Hara - Way, entre outros pensadores contemporâneos, que têm assinalado a necessidade do estudo 
integrado de humanos, seres não humanos e coisas materiais, na medida em que o ser humano não é apenas o seu corpo em contacto ou em relação com outros seres humanos.

Bruno. Latour refere especificamente o papel da Arqueologia no estudo das "coisas". Segundo o autor, no momento da descoberta, o objeto causa espanto, curiosidade, e chama a atenção porque se tratade algo "novo", pois a distância no tempo fez o ser humano ignorante ou desajeitado em relação ao seu uso. No entanto, assim que o seu estudo permite a escrita sobre a "cultura" ou a "sociedade" em estudo, o objeto cai no esquecimento, é arquivado. Aqui o objeto está desprovido de qualquer agência, de qualquer capacidade de agir. É um intermediário no processo do conhecimento (Latour, 2005, 80).

Segundo Shanks o passado, que apenas "existe" enquanto visão retrospetiva (o que não compromete a ontologia do passado), é um processo criativo, tal como o presente; o passado apenas "é o que foi". É o resultado das múltiplas conexões feitas pelo arqueólogo, as quais extravasam os limites de qualquer contexto particular, espraiando-se para campos antropológicos e históricos, de comparações e conexões. Segundo o autor, os "restos" são recursos na criação e representação do passado. No entanto, obedecem a uma agenda política. É necessário perguntar quem tem acesso a esses recursos, ou seja, quem é que produz passado e em que condições (Shanks, 2007). Ao desarticular o tempo sequencial, a Arqueologia Simétrica propõe o tempo da memória como o tempo do passado arqueológico.

Mas a lembrança do passado é um processo construtivo e criativo, não obedece ao tempo linear e é dinâmica, no sentido em que se faz a cada momento em relação com o presente, com as conexões que articulamos com outras pessoas, objetos ou animais. Witmore refere "Se bem que a medição do tempo é extremamente importante, não é o tempo em si" (Witmore,2007, 310) e sublinha que o arqueólogo pode estudar os múltiplos passados materiais das 
O Lugar das comunidades na preservação do património...

paisagens, sítios, elementos e coisas como uma reunião de tempos díspares. Salienta também que as "inovações" de hoje trazem na bagagem a tradição, o saber fazer, as "inovações" passadas. As novas tecnologias do mundo contemporâneo podem ser estudadas em relação aos apontamentos do passado que trazem inscritos.

$\mathrm{O}$ retorno aos materiais, às coisas, abdica das metanarrativas e da história sequencial. Não há sequência cronológica nos contextos que escavamos ou nos quais vivemos. $O$ registo arqueológico é incompleto, fragmentário, fragmentado. No entanto, não podemos lamentar esta incompletude nem preencher as suas lacunas. Os objetos remetem para a memória. A memória que é sempre incompleta e fragmentária, reescrita ao longo do tempo, não sequencial, que pode ser confusa ou criada. A "cultura material" tão discutida entre os arqueólogos só faz sentido nesta linha, ou seja, os materiais são espelhos da sociedade que os criou ou reveladores de intenções passadas, da cultura (por oposição aos materiais não transformados pela mão humana, às coisas da natureza).

I. Hodder publica, em 2012, Entangled. An Archaeology of the Relationships between Humans and Things. Esta obra, ainda que assente em perspetivas distintas das que norteiam o trabalho desenvolvido pela Arqueologia Simétrica, propõe também um olhar atento às coisas mas sobretudo às teias de relações entre coisas e seres humanos, entre coisas, e entre seres humanos (próximo da definição de Arqueologia Simétrica de Shanks). Hodder demora-se nas possíveis relações, nos múltiplos e distintos emaranhados em que nos encontramos enredados.

Ao contrário da obra de Olsen, onde não conseguimos uma definição exata do que é / são a(s) coisa(s), Hodder esclarece que apesar do arqueólogo se concentrar nas coisas materiais, este lida com "the material weight of the past" (Hodder, 2012, 211), maioritariamente feitas pela mão humana, as "coisas" integram também animais, plantas, a argila e a água, e mesmo o que não 
deixa rasto material, como pensamentos, sentimentos, cheiros ou o que é apenas enunciado. As coisas podem ser o fluir da energia, da informação, mas também o são as instituições. Mas estas coisas não são inertes: transformam-se, caem, morrem, crescem, escasseiam, modificam- se.

As vozes que defendem um regresso aos materiais não são novas no contexto arqueológico, sobretudo através dos Estudos em Cultura Material, focados essencialmente no consumo de objetos no mundo contemporâneo. No entanto, como o próprio nome indica, estas abordagens parecem naturalizar a dicotomia entre cultura e natureza e, segundo Ingold, baseiam-se na análise dos objetos enquanto entidades fixas e não enquanto coisas em transformação (Ingold, 2011: 26).

T. Ingold, antropólogo profundamente ligado à Arqueologia e precursor na articulação de campos do saber que se estudam normalmente autonomamente (Antropologia, Arquitetura, Arqueologia e Arte), defende que deveríamos "take materials seriously" (Ingold, 2011, 31). O autor sublinha que a Arqueologia e a Antropologia estão presas ao termo "materialidade", o que as distancia dos materiais. Os materiais são entendidos por Ingold como parte de um mundo em constante transformação, um mundo vivo, e, nesse sentido, os objetos não "existem" no mundo material, mas "ocorrem". Ou seja, não são peças que podem ser definidas objetivamente nem apreendidas subjetivamente mas sim experienciadas. Assim, as propriedades dos materiais não se resumem a medições e descrições da forma e da cor mas "every property is a condensed story. To describe the properties of materials is to tell stories of what happens to them as they flow, mix and mutate" (Ingold, 2011, 30).

Em Overcoming the Modern Invention of Material Culture, editada por V. O. Jorge e J. Thomas, apresentam-se um conjunto de contribuições apresentadas no Theoretical Archaeology Group, em Exeter, 2006. Foi colocada em questão a divisão entre cultura e 
O Lugar das comunidades na preservação do património...

natureza subjacente à expressão "cultura material" e Thomas propõe "colocar de lado" a expressão "cultura material", na medida em que esta pode reduzir o estudo das coisas materiais feitas pelo ser humano a peças cápsula da cultura que os produziu. No entanto, alerta para o facto de os materiais transformados pela mão humana dizerem mais ao arqueólogo que os outros, os que não foram feitos, formados pelo ser humano (Thomas, 2006-2007, 16). V. O. Jorge sublinha a tentação a que a Arqueologia cede ao objetificar tudo o que estuda, não dando espaço à estranheza de todos os dias, às nuances do mundo (Jorge, 2006-2007).

Nesta discussão e análise sobre o objeto e a cultura material, é importante referir que ao estudarmos minuciosamente os materiais e o contexto em que estão depositados, também nos diz muito sobre o homem e o simbolismo da época, a sua religiosidade, etc. Diversos trabalhos dedicados ao estudo de materiais, ao detalhe das coisas e das suas relações, possibilitaram a criação de outras perspetivas, de outras relações, e a emergência de novos entendimentos. Pela primeira vez, em 1984, os autores J. Thomas e C. Richards, propõem a existência de "deposições intencionais" em contextos pré-históricos, resultado do estudo detalhado dos fragmentos cerâmicos, peças líticas, objetos em osso, e suas relações, provenientes dos buracos de poste de Durrington Walls. Outros autores, como D. Garrow, E. Beadsmoore e M. Knight, em 2005, detetaram a presença de materiais fragmentados pertencentes à mesma peça em distintas fossas contiguas, o que permitiu aumentar o leque interpretativo relativo ao processo de enchimento destas estruturas em negativo, as quais, devido a outros estudos já anteriormente realizados, também atentos aos materiais e às suas relações, tinham já colocado em questão a velha explicação destas unidades como silos ou lixeiras. Em contexto peninsular o trabalho de Márquez Romero e Jiménez Jáimez (2010) aborda este e outros problemas 
interpretativos de sítios com estruturas em negativo no sudoeste peninsular.

O estudo das coisas permitiu "inferir" outras coisas ou estudar outras relações. Os exercícios arqueológicos fizeram-se através do olhar para, mas também, das coisas. No entanto, estes trabalhos não se inserem na chamada Arqueologia Simétrica ou na Arqueologia das Relações, mas parecem já intuir esta direção e trabalham-na. É necessário olhar para as coisas não como meios para encontrar o "índio por detrás do artefacto" ou a sociedade que o produziu, manipulou e descartou, não como forma de sentir experiências passadas ou como meios para encontrar significados metafóricos, não como o resultado de um projeto, de um plano prévio que é concretizado, mas o desafio parece ser o de descrever as possíveis pequenas histórias. E sobretudo as pequenas histórias que nos situam e nos comprometem. Como diz Walter Benjamin: "E engana-se e priva-se do melhor quem se limitar a fazer o inventário dos achados, e não for capaz de assinalar, no terreno do presente, o lugar exacto em que guarda as coisas do passado" (Benjamin, $2004,220)$. No contexto peninsular, onde os temas de desigualdade social e sobre relações de poder continuam a orientar a investigação arqueológica, as críticas à Arqueologia Simétrica revelam a estranheza perante o "inusitado afecto pelos materiais" (Martinez, 2007, 317), quando os seres humanos são e foram os corpos de injustiça social, que denunciam desigualdades (por vezes gritantes) no acesso às "coisas". E, se a arqueologia é a "ciência das coisas", esta torna-se ciência quando o objeto é considerado como algo que serviu noutro tempo, mas que é testemunho de sociedades ou mundos culturais passados. Para a arqueologia é importante a contextualização quer do objeto, quer do espaço onde este foi encontrado e a prática da arqueologia "deve ser entendida como antropologia cultural de uma sociedade passada" (Alarcão: 2000,p 25). 
O Lugar das comunidades na preservação do património...

Depois de uma breve análise pelas mais recentes correntes na Arqueologia enquanto ciência, é importante que nos debrucemos sobre a Arqueologia enquanto prática. Na história, em geral, ficam de fora os factos inconsequentes, como os quotidianos, os gestos comuns, as atividades diárias mas, se conseguirmos comparar a realidade atual e as questões contemporâneas, nas ações realizadas no âmbito do património arqueológico, conseguiremos um maior interesse e empatia das pessoas por esse património. Os objetos que o arqueólogo desenterrou não permitem entrever a consciência individual de quem os usou, mas podem desvendar as representações coletivas e códigos sociais. Para autores como Tilley " o passado é uma construção produzida socialmente, algo feito aqui e agora, no presente" (Tilley,1990).

O património arqueológico contribui para uma consciencialização da "antiguidade" da comunidade, pela própria comunidade e que são hoje aquilo que foram construindo ao longo do tempo, num determinado espaço, criando características próprias, continuando com os costumes, as tradições e, às vezes, combatendo as mesmas as lutas e injustiças sociais.

O património arqueológico e a sua relação com a comunidade e seu território são ponderados através do conceito de arqueologia pública ou arqueologia comunitária. O termo foi utilizado pela primeira vez em 1972, por Charles MacGimsey no seu livro Public Archeology e assenta na premissa da participação das comunidades locais nos projetos de arqueologia, que se iniciou nos Parques Naturais que surgiram pela Europa nos anos 70 e 80 . Define-se como o estudo das relações entre a arqueologia e a sociedade atual, em todos os seus âmbitos e implicações sociais, politicas e económicas e nasce como uma resposta a uma necessidade criada pela gestão do património arqueológico.

No brasil a musealização da arqueologia tem sido tratada por Cristina Bruno (Bruno, 1995, 1996, 2004, 2007) e a arqueologia pública por Paulo Funari (Funari, 2008). Países como o Brasil, 
México, Argentina e Chile têm trabalhado a relação arqueologia memória - comunidade, com algumas investigações desenvolvidas (Montenegro e Aparicio, 2013; Zabala e Fabra, 2012; Funari, 2012).Os projetos desenvolvidos em Neuchatel, na Suíça, constituem também um excelente exemplo de boas práticas na relação da arqueologia com a comunidade e com o público. Em contexto nacional, Luís Raposo tem sido o autor que mais tem abordado questões relacionadas com museus de arqueologia (Raposo, 1997, 1999, 2004, 2009) e os trabalhos desenvolvidos pelo Campo arqueológico de Mértola constituem também uma referência.

Mas se a Arqueologia for analisada na perspetiva da Educação podemos ter outros conceitos associados à arqueologia, como a arqueologia formal e a arqueologia informal. $\mathrm{Na}$ arqueologia formal podemos incluir os estudos de carácter científico e a arqueologia em contexto de universidade. $\mathrm{Na}$ arqueologia informal podem estar incluídas todas as atividades relacionadas com o património arqueológico, desde as visitas guiadas, aos serviços educativos, comunicações à comunidade, reconstituições e etc.

Ao longo da pesquisa que tenho feito no âmbito do programa de doutoramento e pela minha experiência enquanto arqueóloga em área urbana, constato que ficam de fora "outras" arqueologias. Na minha análise da arqueologia como prática, considero importante incluir a "arqueologia" praticada pelo curioso, de forma fortuita ou clandestina, que pode ser considerada como ilegal pela comunidade de arqueólogos no seu geral, mas que ao longo da história da Arqueologia como ciência teve um papel fundamental. Este conceito de uma prática arqueológica que existe mas raramente é falada ou escrita, a que chamo de "clandestina" (por não estar sujeita à chancela das instituições que tutelam o património arqueológico e por não ser praticada pelo arqueólogo), deve ser tida em conta quando pensamos no património 
O Lugar das comunidades na preservação do património...

arqueológico local e na sua relação com a comunidade. Qual é a povoação ou cidade que não tem uma personagem que possui uma coleção de objetos antigos, que contava (alguns deixaram notas e livros escritos) histórias de povos antigos que habitavam no território? Não devemos subestimar o conhecimento destes indivíduos, quando este foi movido pela curiosidade e pelo querer conhecer a história dos seus antepassados e da sua comunidade e, principalmente pelo afeto.

Outra "faceta" da arqueologia que "descobri" no decorrer da minha atividade profissional prende-se com o papel ativista que o arqueólogo pode assumir quando desempenha as suas atividades e, principalmente durante a intervenção arqueológica em ambiente urbano. $\mathrm{O}$ que me fez pensar nesta faceta ou conceito associado à arqueologia foi, durante um dia em estava a fazer um acompanhamento de abertura de valas numa das ruas mais antigas do centro histórico de Setúbal, encontrando me a fazer um registo de um piso antigo colocado a descoberto pela vala, quando uma moradora, senhora já idosa, me perguntou: "Ó menina! Então o que está a fazer metida numa trincheira?". Esta observação originou logo uma conversa sobre o que estava ali a fazer, porquê e expliquei o que estava a desenhar e a senhora, com o seu interesse e perplexidade por me ver "metida numa trincheira", lá foi entendendo a arqueologia e tomando consciência que se tratava de um piso idêntico ao que ela pisava hoje, mas que fora pisado em outros tempos e, quem sabe, por algum ascendente seu. A conversa terminou e mais tarde não conseguia esquecer a observação da senhora..."metida numa trincheira". Afinal eu praticava uma Arqueologia de Trincheira. O termo pode ter duas análises no que diz respeito à arqueologia, a literal, porque neste tipo de acompanhamento arqueológico o arqueólogo está, de facto, numa trincheira e a metafórica porque é uma arqueologia de resistência. Na análise metafórica do termo trincheira, podemos associar as dificuldades com que se debate o arqueólogo neste tipo 
de intervenção. Pelas suas características são intervenções que são realizadas de forma rápida com a pressão do empreiteiro, para avançar com a obra sem tempos de espera e respetivos prejuízos. A pressão do organismo público que manda fazer a obra e não quer gastos adicionais ou, por motivos políticos, porque uma obra parada é motivo de desagrado da população e finalmente a própria comunidade também pressiona, porquanto a obra lhes traz inconvenientes no acesso às suas casas, no seu quotidiano. No entanto, é neste tipo de intervenção que o arqueólogo pode ter um papel mais ativista e contribuir para a mudança de mentalidades dos empreiteiros, dos organismos públicos e das comunidades perante o património arqueológico. A sua posição de trincheira permite-lhe o contacto direto, em tempo real com os outros e tem um papel de resistente na luta que trava na preservação do património arqueológico, assente numa perspetiva participativa entre a arqueologia e a comunidade e atenta às dinâmicas sociais a esta intrínseca.

Em suma, Comunidade e Identidade, Património Arqueológico, Arqueologia e Práticas Arqueológicas são temas que pretendo analisar no meu projeto de investigação no âmbito do programa de doutoramento em museologia social, onde se propõe mapear os sítios arqueológicos do concelho de Setúbal, identificando os sítios com relevância para a (s) comunidade (s) e com os quais se identificam, caracterizando as memórias associadas aos sítios arqueológicos com ligação às comunidades e analisar a relação que as comunidades estabelecem com estes sítios (sítios arqueológicos/sítios de romaria). Pretende-se estudar não só as relações estabelecidas com o património, mas também a possibilidade de construção de novas memórias, que por sua vez contribuem para a preservação do património arqueológico. Ao analisar a relação que a comunidade estabelece com os sítios arqueológicos, tomamos consciência de questões essenciais para a preservação patrimonial, entre as quais: - a relação dos sítios com a 
O Lugar das comunidades na preservação do património...

memória local e coletiva (lendas, procissões e cultos etc); - a relação da descoberta do sítio com possíveis impactos socioeconómicos na população e porquê; - a relação da divulgação e comunicação do património arqueológico com a perceção de cada comunidade com o património cultural; - as diferentes manifestações das políticas culturais aplicadas e as repercussões param o património e para as comunidades.

Na primeira análise já desenvolvida constatamos que em 104 sítios arqueológicos identificados, 13 estão musealizados, dos quais 6 tem dinamização e 9 estão associados a lendas e procissões. No que diz respeito à dinâmica Sítios arqueológicos/Sítios de romaria, existem em Setúbal alguns exemplos tais como, as Ruinas romanas de Tróia /Festas religiosas de Nossa Senhora de Troia, a Fortaleza do Outão /Festas de Nossa Senhora de Tróia e de Nossa Senhora da Arrábida, a Lapa de Santa Margarida (com ocupação pré-histórica e presença de vestígios do Homo de Neanderthal) / lenda associada e culto religioso e o Baluarte da Conceição /Festas do Nosso Senhor do Bonfim e de Nossa Senhora de Troia. A caracterização dos contextos identitários permitirá uma análise da relação estabelecida entre a comunidade e o património arqueológico, através de uma abordagem multidisciplinar que pretende caracterizar e distinguir as práticas museológicas e patrimoniais e o seu contributo para a preservação do património arqueológico. $\mathrm{O}$ tratamento dos dados e sua interpretação serão enquadrados por conceitos estruturantes como memória (mas também o esquecimento), identidade, comunidade, património e arqueologia e desenvolvimento local.

A par da relação que a comunidade estabelece com o sítio arqueológico, pretende-se igualmente analisar as formas de divulgação e de comunicação da arqueologia como ciência e apresentar propostas de atuação, com base na experiência com as comunidades de Setúbal. Será privilegiada uma abordagem multidisciplinar, relacionando dados históricos, económicos, sociais, 
culturais e da museologia visando esclarecer o entendimento comunitário e sua atuação na preservação e valorização do património arqueológico, considerando as particularidades da história local, da população e seu contexto histórico, que possibilitam ou não um melhor entendimento do património e da aculturação deste pela comunidade.

Propõe-se também a análise da (s) arqueologia (s) de Setúbal, ou seja, as várias vertentes da arqueologia setubalense, ao longo dos tempos, quer seja na perspetiva formal (estudo cientifico do sítio arqueológico), na perspetiva informal (com as atividades desenvolvidas e o seu contributo para a preservação do sítio) e numa perspetiva de arqueologia pública, com consciência social. Será igualmente analisada a presença, ao longo da história, de uma arqueologia que poderá ser denominada como "clandestina", caracterizada por achados fortuitos pela população local (maioritariamente pela comunidade piscatória), mas que tem contribuído para a preservação dos sítios arqueológicos, através das memórias e das histórias a estes associados, contadas por personagens bem conhecidas dos setubalenses e que de alguma forma contribuíram para a consciencialização da existência do património arqueológico e da importância para a (s) história (s) e identidade (s) setubalense. O termo Arqueologia de Trincheira (uma arqueologia de Resistência) terá uma análise mais detalhada e será proposta uma definição.

O património arqueológico, a sua musealização e apresentação pública pode contribuir para a consolidação da identidade de uma comunidade e para o fortalecimento das suas memórias. A sociomuseologia e as questões a ela associadas, largamente documentadas em variados estudos sobre o tema, são pertinentes para a forma como o tratamento do património arqueológico é realizado e para a forma como este é apresentado. A arqueologia é uma disciplina onde o imaginário está desde sempre associado, talvez pela ausência de textos nos contextos, 
O Lugar das comunidades na preservação do património...

porque se nos apresenta incompleto na sua fisicalidade e, como tal, desperta em quem o vê o poder da imaginação, do sonho. Mas também é sinónimo de uma organização social, com ou sem justiça, com maior ou menor liberdade, em muito idêntica à realidade atual. A arqueologia é uma ciência que, pelas suas características, se pode aproximar mais da comunidade pela relação que esta tem com o quotidiano e pelo facto de suscitar o imaginário de cada um. É uma ciência que pretende estudar o individuo no "grau zero de individualização" (Alarcão:2000:p.7).

As marcas deixadas pelo homem, através dos seus objetos e das suas construções são também uma marca de identidade.

\section{Bibliografia:}

Alarcão, Jorge de (2000). A Escrita do Tempo e a sua Verdade (Ensaios de Epistemologia da Arqueologia). Colecção Caminhos. Edição Quarteto.

Abreu, Maurício de Almeida. Sobre a memória das cidades. Revista da Faculdade de Letras - Geografia, Vol. XIV, Porto, 1998, p.77-97. Benjamin, W. (2004) - "Escavar e Recordar". In Imagens de Pensamento. Ed. e tradução João Barrento. Lisboa: Assírio \& Alvim, pp. 219-220.

Bruno, Maria Cristina Oliveira. (1996). Museologia e Comunicação. Lisboa: Universidade Lusófona de Humanidades e Tecnologias, 1996.

Bruno, Maria Cristina Oliveira (1999). Musealização da arqueologia: um estudo de modelos para o projecto de Paranapanema. Cadernos de Sociomuseologia, N.o 17. Lisboa: ULHT.

Bruno, Maria Cristina Oliveira (2002). A museologia como uma pedagogia para o patrimônio. Ciências \& Letras, ํo 31. Porto Alegre: 2002. 
Freire, Paulo (1967). Educação como prática da liberdade. Paz e Terra. Edição Civilização Brasileira. Rio de Janeiro.

Funari, P., Oliveira, N. \& Tamanini, E. (2008) - Arqueologia Pública no Brasil e as novas Fronteiras. Praxis Archaeologica. Vol. III, p. 131-138. Acedido a 28 de Junho de 2016 em http://www.praxisarchaeologica.org/PT/003_pt.php Halbwachs, M. - La memoire colletive, PUF, Paris, 1950 Huyssen, Andréas. Seduzidos pela Memória. Arquitetura, Monumentos, Mídia.

RJ: Aeroplano, 2000.

Hodder, I. (2012) - Entangled. An Archaeology of the Relationships between Humans and Things. Malden: Wiley-Blackwell.

Ingold, T. (2011) - "Materials against materiality". In Being Alive. Essays on Movement, Knowledge and Description. London/New York: Routledge, pp. 19-32.

Jones, S. (1996) - Discourses of identity in the interpretation of the past, in in Graves - Brown, P. Jones, S. and Gamble, C. (eds) Cultural Identity and Archaeology: The construction of European communities. London: Routledge, 62-80.

Jorge, Vítor Oliveira (2000). Arqueologia, Património e Cultura. Instituto Piaget. 2000.

Jorge, Vítor Oliveira (2004). Património: neurose contemporânea? Alguns apontamentos sobre o papel da memória colectiva na idade da fragmentação. Comunicação apresentada na $8^{a}$ Mesa Redonda de Primavera realizada na Faculdade de Letras da Universidade do Porto nos dias 26 e 27 de Março, 2004.

Latour, Bruno (2005). Reassembling the social: an introduction to actor-network-theory. Oxford New York: Oxford University Press. ISBN 9780199256044.

Moutinho, Mário C. (1989). Museus e Sociedade. Cadernos de Património.

Moutinho, Mário (1993). Sobre o conceito de museologia social. In cadernos de Sociomuseologia, no 1, pp 7-9. ULHT. 
O Lugar das comunidades na preservação do património...

Nora, Pierre. Entre história e memória: a problemática dos lugares. Revista Projeto História. São Paulo, v. 10, p. 7-28, 1993.

Olsen, B. (2012) - "After Interpretation: Remembering Archaeology". Current Swedish Archaeology. 20: 11-34.

Olsen, B. (2013) - In Defense of Things. Archaeology and the Ontology of Objects.

Plymouth: Altamira Press.

Primo, Judite (2006). A importância dos museus locais em Portugal. In cadernos de Sociomuseologia. № 25 p 41- 62. ULHT.

Shanks, M. (2007) - "Arqueología Simétrica". Complutum. 18: 292295.

Thomas, J. e Jorge, V.O.(eds) (2006-2007) - "The trouble with material culture". (eds.). Overcoming the Modern Invention of Material Culture. Porto: ADECAP, pp. 11-23 (Journal of Iberian Archaeology. 9-10, special issue).

Varine, Hugues de, "Politiques muséales et stratégies de développement local et

national. De l'exhibitionisme à la commucation sociale (resumé)",, comunicação

apresentada no IV Atelier Internacional da Nova Museologia, MINOM, Aragão, 1987 